\title{
Enfermedad periodontal como factor de riesgo de condiciones sistémicas.
}

\section{Periodontal Disease as a Risk Factor for systemic conditions.}

Carla Pretel-Tinoco ${ }^{1, a}$, Beatriz Chávez Reátegui ${ }^{2, b}$.

\section{RESUMEN}

La enfermedad periodontal es una agresión patógena e inflamatoria, continua a nivel sistémico, por la gran cantidad de superficie de epitelio ulcerado de las bolsas que permite a través de 3 mecanismos el paso de bacterias y sus productos al organismo. Es por esto que se presenta a dicha enfermedad como un factor de riesgo importante a tener en cuenta en la aparición de ciertas alteraciones sistémicas como resultados adversos del embarazo (parto pretérmino y bajo peso al nacer), enfermedades cardiovasculares (endocarditis bacteriana, infarto del miocardio, cardiopatía isquémica y aterosclerosis), respiratorias (neumonía bacteriana, bronquitis y enfermedad pulmonar obstructiva crónica) y diabetes mellitus.

\section{Palabras clave: ENFERMEDAD PERIODONTAL, FACTOR DE RIESGO, ENFERMEDADES SISTÉMICAS.}

\begin{abstract}
Periodontal disease is an inflammatory pathogenic aggression, continuous systemic level, by the large number of ulcerated epithelial surface of the bags allows through three mechanisms the passage of bacteria and their products to the body. This is why the disease is presented as an important risk factor to consider in the development of certain systemic disorders such as adverse pregnancy outcomes (preterm birth and low birth weight), cardiovascular disease (bacterial endocarditis, myocardial infarction, ischemic heart disease and atherosclerosis), diseases (bacterial pneumonia, bronchitis and chronic obstructive pulmonary disease) and diabetes mellitus.
\end{abstract}

Key Words: PERIODONTAL DISEASE, RISK FACTORS, SYSTEMIC DISEASES.

\footnotetext{
Facultad de Estomatología Roberto Beltrán. Universidad Peruana Cayetano Heredia. Lima, Perú.

2 Asociación Peruana de Periodoncia y Oseointegración. Lima, Perú.

a Cirujano Dentista.

b Magister en Estomatología.
} 


\section{INTRODUCCIÓN}

El término enfermedad periodontal engloba un grupo de enfermedades infecciosas que dan como resultado una inflamación de la encía y tejidos periodontales y una pérdida progresiva del tejido óseo que ocurre con el tiempo; sin embargo es caracterizada por episodios de actividad e inactividad.

En sentido amplio, el término factor de riesgo puede denotar un aspecto del comportamiento personal o del estilo de vida, una exposición al ambiente o un rango congénito o heredado del cual se sabe sobre la base de evidencias epidemiológicas, que está asociado con estados que se vinculan con la enfermedad (1).

En la actualidad y tras numerosos estudios epidemiológicos la enfermedad periodontal se asocia con alteraciones sistémicas; como resultados adversos del embarazo, enfermedades cardiovasculares, respiratorias y diabetes mellitus; por la gran cantidad de superficie de epitelio ulcerado de las bolsas que permite a través de mecanismos el paso de bacterias y sus productos al organismo.

\section{PERIODONTITIS COMO FACTOR DE RIES- GO DE ENFERMEDADES SISTÉMICAS.}

La enfermedad periodontal es una agresión patógena e inflamatoria, continua a nivel sistémico, por la gran cantidad de superficie de epitelio ulcerado de las bolsas que permite a través de 3 mecanismos el paso de bacterias y sus productos al organismo (2).

- Infección metastásica o bacteriemia: los microorganismos ingresan al torrente sanguíneo, no son eliminados y se diseminan.

- Daño metastásico: por las endotoxinas y lipopolisacáridos liberados y letales para las células.

- Inflamación metastásica: por las reacciones antígeno anticuerpo y la liberación de mediadores químicos (2).

\section{Complicaciones en el embarazo: Parto pretér- mino y bajo peso al nacer (PP y BP)}

Los niños prematuros nacen antes de que se complete las 37 semanas de gestación. (3). Estudios mencionados por Offenbacher han demostrado una asociación entre infección y parto pretérmino. La primera evidencia de esa asociación envuelve el aumento de la prevalencia de infecciones de tracto genitourinario en madres con complicaciones en embarazo como el PP y BP. A pesar del papel establecido de las infecciones genitourinarias en la biopatología del nacimiento pretémino las mujeres con trabajo de parto prematuro no siempre presentan cultivos positivos del líquido amniótico, hecho que dio origen a la hipótesis de que el nacimiento pretérmino podría estar mediado en forma indirecta por infecciones distantes que generarían traslocación de bacterias, vesículas bacterianas o liposacáridos en la circulación sistémica. La pregunta que emerge es saber qué es lo que estimula el incremento de citoquinas y el consecuente incremento del nivel de prostaglandina visto en PP en pacientes sin evidencia de infección genitourinaria (4).

El parto prematuro ocurre por la síntesis de prostaglandinas, directamente por las bacterias y por sus productos microbianos y también por la respuesta inflamatoria que ocurre dentro de la cavidad uterina y en el feto. Las citoquinas producidas: interleuquinas 1, 6 y 8, FNT, factor activador plaquetario, factor activador de colonias, proteína inflamatoria de macrófagos contribuyen al desencadenamiento del parto prematuro y a la morbimortalidad perinatal. Las citoquinas pro inflamatorias secretadas por la respuesta fetal y/o materna se presentan en respuesta a la invasión microbiana de la cavidad amniótica. Esta respuesta inflamatoria fetal sistémica es muy importante en el desencadenamiento del parto prematuro y en la morbilidad perinatal (5).

La posibilidad de que las infecciones periodontales puedan formar parte de esas infecciones maternas que influyen negativamente sobre el pronóstico del parto fue planteada por primera vez a finales de la década de 1980. En casos de inflamación gingival ocurren con frecuencia bacteriemias transitorias que llegan hasta los tejidos placentarios y así provean el impulso inflamatorio para la inducción del trabajo de parto (5).

Se postula que bacteriemias transitorias que ocurren en pacientes con periodontitis y gingivitis con sus productos bacterianos llegan a la placenta y membranas por vía hematógena y producen el efecto inflamatorio que induce el parto prematuro. Se ha encontrado que la detección de IgM (+) en cordón umbilical para $F$. nucleatum, $C$. rectus y $P$. gingivalis y para $C$. rectus, F. nucleatum, $P$. micros, $P$. nigriscens y $P$. in- 
termedia es más frecuente en los niños prematuros que en los niños de término.

También se ha encontrado que los fetos con IgM $(+)$ para patógenos orales, tienen mayor riesgo de parto prematuro $<$ de 35 semanas cuando tienen respuesta inflamatoria, proteína $\mathrm{C}$ reactiva, IL-1, IL-6, factor de necrosis tumoral (TNF) y prostaglandina E (PGE) aumentada.

En otra serie se sugiere la ruta oral hematógena de la propagación bacteriana de la infección. Esta hipótesis se sustenta por hallazgo de similitud de cepas de F. nucleatum en el $83 \%$ a nivel subgingival y en líquido amniótico en embarazadas con parto prematuro y membranas intactas.

La importancia de la inflamación en la relación enfermedad periodontal y parto prematuro se aprecia en estudio que encuentra que los niveles de IL-1, PGE2 en el fluido crevicular gingival y la PGE2 en sangre materna, son mayores en las madres con recién nacidos de bajo peso y prematuros que en las madres con partos de término.

La hipótesis más aceptada sostiene que las bacterias periodontales, actuarían como un reservorio crónico de endotoxinas y lipopolisacáridos, que estimularían la liberación constante de mediadores inflamatorios y citoquinas, que por vía hematógena desencadenarían el parto prematuro (6).

En un estudio realizado por Isaac y Col (7), que tenía como objetivo dar a conocer la relación entre enfermedad periodontal y niños con bajo peso al nacer; se presentaron 234 mujeres embarazadas, 54 pertenecían al grupo con tratamiento de la enfermedad periodontal, 68 al grupo control I (sin enfermedad periodontal), 112 al grupo control II (con enfermedad periodontal sin tratar). Dio como resultado que la frecuencia de nacimiento de niños con bajo pesar al nacer fue similar para el grupo control I y las mujeres que tenían tratamiento de la enfermedad periodontal y menor comparado a los del grupo control II. Estos resultados sugieren el éxito del tratamiento periodontal en mujeres que sufren de enfermedad periodontal durante su embarazo (7).

Engebretson y Col, en octubre 2000 (8), en un estudio realizado en mujeres embarazadas constituye- ron dos grupos, estando el primero conformado por 74 embarazadas, en quienes el estado periodontal fue evaluado y además recibieron tratamiento periodontal por medio de raspaje, alisado radicular e instrucción sobre higiene bucal. El segundo grupo compuesto por 90 embarazadas no recibió ningún tratamiento dental prenatal. La prevalencia de niños prematuros con bajo peso fue de 27 casos (16,5\%). Resultados sorprendentes fueron: de los 27 casos, la ocurrencia de niños prematuros con bajo peso se dio en 17 casos en quienes no recibieron intervención periodontal y sólo en 10 casos de las embarazadas que recibieron terapia periodontal (8).Se encontró que la enfermedad periodontal es más severa en madres con partos de pretérmino que de término. A su vez la enfermedad periodontal severa es más frecuente en embarazadas con parto prematuro (membranas intactas y rotura prematura de las membranas) y nacimiento de niños de bajo peso, que en las mujeres con partos de término. Fig1.

Fig 1. Modelo propuesto para la relación entre enfermedad periodontal y resultados adversos del embarazo.

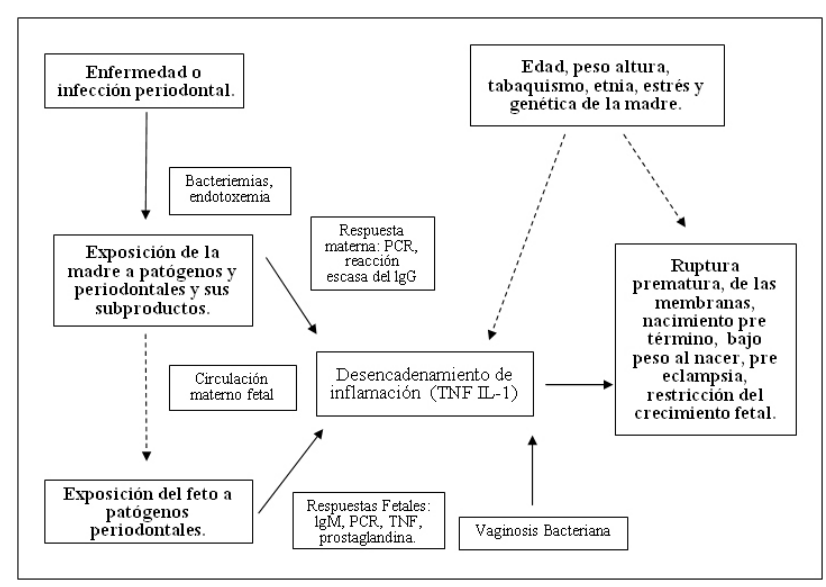

(Lindhe, Lang, Karring. Periodontología Clínica e Implantología Odontología. Editorial Médica Panamericana; 2009)

\section{Enfermedades cardiovasculares}

La enfermedad cardiovascular usualmente es el resultado del largo proceso de la ateroesclerosis, cuya placa ateromatosa está compuesta de un cuerpo lipídico, depósitos calcificados y gran cantidad de tejido fibroso; que progresivamente tiende a reducir el flujo sanguíneo durante los periodos de mayor demanda de oxígeno (9).

Con frecuencia, en los pacientes que debutan con algún evento cardiovascular no es posible identificar 
alguno de los factores de riesgo tradicionales, tales como tabaquismo, dislipidemia, hipertensión arterial, etc. En la búsqueda de nuevos factores de riesgo ha adquirido importancia el rol de la infección, dentro del cual se identifica la infección periodontal.

Estudios epidemiológicos han demostrado asociación entre periodontitis avanzada con una mayor incidencia de eventos coronarios. De Stefano investigó la relación entre el estado periodontal de personas asintomáticas con las tasas de morbilidad cardiovascular, en un seguimiento de 14 años. Ellos encontraron que los sujetos con periodontitis avanzada al comienzo del estudio, tenían un riesgo $25 \%$ mayor de presentar accidentes cardiovasculares que las personas sin enfermedad periodontal (10).

A finales de 1990 el hallazgo de organismos periodontopáticos en la placa ateroesclerótica, dio inicio a una serie de estudios en cultivos celulares y modelos animales que fueron encaminados a dilucidar los mecanismos fisiopatológicos de estas bacterias en el desarrollo y ruptura del ateroma.

Scannapieco y sus colegas efectuaron un análisis sistemático reciente de la evidencia entre la enfermedad periodontal y la enfermedad cardiovascular. Los investigadores hicieron la siguiente pregunta central ¿La enfermedad periodontal influye en el inicio o progreso de la aterosclerosis y por lo tanto de la ECV? Según sus análisis concluyeron en que la enfermedad periodontal podría estar moderadamente asociada con la aterosclerosis, el infarto del miocardio y los eventos cardiovasculares (11).

Los estudios experimentales de asociación causal entre enfermedad periodontal con la ateroesclerosis se iniciaron en 1999, cuando Dorn y Col. demostraron la invasión de $P$. gingivalis y $P$. intermedia en células endoteliales y de músculo liso. Las bacterias estudiadas incluían $A$. actinomycetemcomitans, $T$. forsythia, $P$. gingivalis y $P$. intermedia. La investigación mostró la presencia de por lo menos uno de los periodontopáticos en el $44 \%$ de las 50 muestras de placa ateromatosa.

Se han propuesto diferentes mecanismos que vinculan la invasión vascular por periodontopáticos con el desarrollo de la placa ateromatosa.
Chou y Col encontraron que el aumento en la expresión de genes inflamatorios en células endoteliales era producido por la cepa invasora de $P$. gingivalis. El aumento de la expresión de proteínas inflamatorias en células endoteliales sugiere que la invasión por $P$. gingivalis incrementa la migración vascular de leucocitos y el desarrollo de ateroesclerosis. Conjuntamente con los cambios secundarios a la infección por $P$. gingivalis descritos en las células endoteliales, de la placa ateroesclerótica, se han aislado líneas de células T CD4+ y CD8+ especificas para P. gingivalis.

\section{A. Relación entre enfermedad periodontal y ate- rosclerosis}

La aterosclerosis, es conocida como el estrechamiento de las arterias debido a la formación de una placa sobre la superficie interna de su pared. Una placa de ateroma contiene todos los patógenos periodontales reconocidos ( $P$. gingivalis, A. actinomycetemcomitans, T. forsythia), que además intervienen en su formación al liberar lipopolisacáridos.

Puesto que existiría asociación epidemiológica entre infección periodontal y aterosclerosis, ¿cuáles serían los mecanismos que explicarían tal asociación?

La periodontitis produce bacteriemias cíclicas y crónicas de bajo grado, que se traducen, además, en mayores niveles de marcadores biológicos de inflamación, tal como es el caso de TNF $\alpha$, interleuquinas 1 y 6 y reacción en cadena de la polimerasa PCR ultrasensible, comparados con pacientes sin enfermedad periodontal.

Otros mecanismos por los cuales puede actuar la EP son a través de la invasión directa de los microorganismos al epitelio coronario y carotídeo provocando várices e insuficiencia coronaria.

Otro mecanismo potencialmente involucrado es la mayor activación de metaloproteinasas, reflejadas en una concentración sérica superior de los productos de degradación del colágeno comparados con pacientes sin enfermedad periodontal (9).

La enfermedad periodontal se caracteriza por una marcada respuesta inflamatoria en los tejidos gingivales. Los componentes estructurales de las bacterias periodontopáticas como los lipopolisacaridos (LPS) intervienen en la liberación de mediadores químicos 
que activan células $\mathrm{T}$ y la formación de ateromas, actúan sobre las metaloproteinasas que intervienen en la desestabilización de las placas de ateroma y actúan sobre la proteína de fase aguda del hígado, y los fibrinógenos que intervienen también en la formación de ateromas. Además estimulan la proliferación vascular del músculo liso, provocando degeneración grasa y coagulación intravascular, que facilita todos estos eventos ya presentados.

Los pacientes con enfermedad periodontal presentan un incremento de los niveles séricos de marcadores inflamatorios como la IL-1, la IL-6 y la TNF- $\alpha$ . Estos marcadores se han correlacionado en varios estudios epidemiológicos con un aumento del riesgo cardiovascular.

Por otro lado, se plantea que los microorganismos y productos bacterianos de la EP, pasan al torrente sanguíneo y se alojan en válvulas anómalas del corazón y en tejidos cardíacos previamente dañados, causando la inflamación del endocardio (4). Fig 2.

Fig 2. Modelo y mecanismos propuestos que vinculan enfermedad periodontal con enfermedad periodontal con enfermedad cardiovascular.

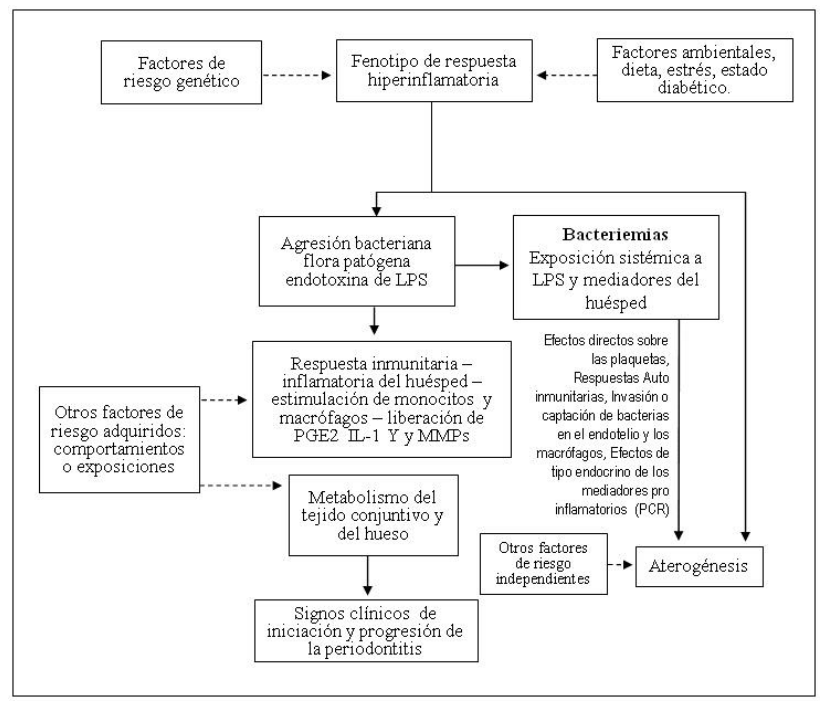

(Lindhe, Lang, Karring. Periodontología Clínica e Implantología Odontología. Editorial Médica Panamericana; 2009)

\section{B. Relación entre enfermedad periodontal y endo- carditis infecciosa}

La endocarditis infecciosa es una infección del revestimiento de las cavidades del corazón y de las válvulas cardíacas, causadas por bacterias, hongos virus u otros microorganismos. La endocarditis bacteriana se refiere específicamente a la infección por agentes bacterianos. El origen de la infección podría ser una bacteriemia transitoria, la cual es común durante diagnósticos y procedimientos quirúrgicos.

Puede ocurrir en la enfermedad periodontal durante el sondaje, los raspados y alisados radiculares y en los tratamientos quirúrgicos, entre otras maniobras. Las bacterias entran a la circulación sanguínea y se adhieren en una zona dañada o receptiva de las superficies del endocardio. Hay pacientes que tiene una predisposición para padecer una endocarditis infecciosa, entre los cuales están aquellos que padecen fiebre reumática, entre otras patologías. En estos pacientes la enfermedad periodontal aumenta el riesgo de padecer esta enfermedad.

Las válvulas del corazón que se han visto dañadas o que son anormales se encuentran en un alto riesgo de adquirir la endocarditis infecciosa, aunque la infección también puede ocurrir en válvulas normales cuando un gran número de bacteria está presente. Los investigadores creen que cuando a un individuo se le diagnostica la enfermedad periodontal, una tarea tan normal como la de masticar o cepillarse puede lastimar el tejido de la encía, permitiendo que la bacteria entre al flujo sanguíneo. La acumulación de esta bacteria en las válvulas del corazón, por lo general, conduce a una infección fatal, a menos que sea tratada.

Los dos microorganismos más asociados a endocarditis infecciosa son streptococcus viridans $y$ staphylococcus aureus. El efecto de estos microorganismos podría ser incrementado en presencia de infecciones orales como periodontitis crónica. Otros microorganismos asociados a endocarditis infecciosa son los gram negativos entre ellos A. actinomycetemcomitan y E. corrodens, que son patógenos periodontales putativos (12).

\section{Enfermedades respiratorias}

La relación entre enfermedad periodontal y enfermedades respiratorias se establece siempre que exista fallo en los mecanismos de defensa. Las patologías más frecuentemente asociadas son: neumonía bacteriana, bronquitis y enfermedad pulmonar obstructiva crónica (13).

La patogenia de la neumonía bacteriana en adultos 
se basa en la aspiración de las bacterias que colonizan la región orofaríngea y cuando fracasan los mecanismos de defensa del huésped, las bacterias se multiplican y causan la infección. Los microorganismos más frecuentemente que se identifican son: streptococcus neumoniae, streptococcus pyogenes, mycoplasma pneumonia y haemophilus influenzae. Estos patógenos orales al aspirarse en pacientes con periodontitis severa desencadenan la liberación de productos como lipopolisacáridos y enzimas bacterianas específicas que modifican la mucosa de la vía aérea, estimulan la respuesta inflamatoria mediada por citoquinas desde las células epiteliales y alteran las condiciones microambientales que permiten la colonización e infección a mucosas por patógenos respiratorios y bacterias orales. Esto facilita la aparición y progresión de enfermedades respiratorias en individuos susceptibles.

La aspiración de bacterias ocurre fundamentalmente del área orofaríngea cuando bacterias gram negativas de las bolsas periodontales y otros patógenos respiratorios, penetran y se extienden por el tracto respiratorio bajo hasta llegar a pulmón. Fig 3A y B.

Fig 3. A Influencia de microflora oral en las infecciones pulmonares. B Colonización de Biofilms hacia vías aéreas inferiores.

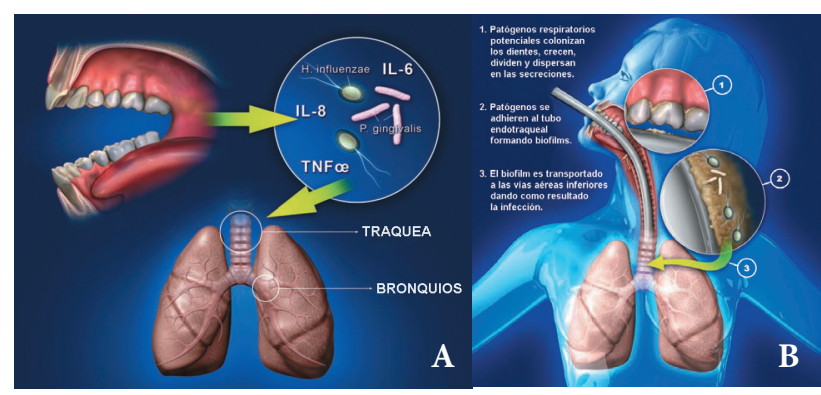

(Inside Dentistry.2007)

Colonización bacteriana que ocurre directamente a la pared vascular por enzimas salivales hidrolíticas que favorecen la adhesión y colonización. Además, las bacterias en el endotelio vascular, alteran la hemostasia endotelial (14).

Liberación de mediadores químicos alteran el epitelio respiratorio propiciando la aparición de todas estas patologías, como las MMP, FNT alfa, IL1, IL6 que destruyen el colágeno, destruyen células endoteliales e interfieren en los mecanismos de defensa (14).

\section{Diabetes Mellitus}

La diabetes mellitus (DM) es una enfermedad compleja de desorden del metabolismo. Se clasifica en tipos 1 y 2. La DM de tipo 1 se desarrolla debido a la producción deficiente de la insulina mientras que la DM de tipo 2 es causada por la utilización deficiente de la insulina.

La relación entre enfermedad periodontal con esta enfermedad se basa en que la presencia de una infección aguda puede predisponer a la resistencia a la insulina. Esto puede ocurrir independientemente de un estado diabético y persistir hasta 3 semanas después de la resolución de la infección. En un estudio longitudinal de pacientes con DM de tipo 2 los que padecían enfermedad periodontal avanzada presentaron un estado diabético significativamente peor que los que tenían enfermedad periodontal mínima.

En pacientes diabéticos de tipo 2 la fase inicial de un tratamiento periodontal, que incluyó motivación y desbridamiento de las bolsas periodontales, redundó en una mejora del control metabólico de la diabetes. Un estudio reciente de Kiran y Col. confirmó estos datos. En un estudio poblacional de los pacientes con DM de tipo 2 y valores de hemoglobina glucosilada de 6-8\% la fase inicial del tratamiento produjeron una notable mejoría en el control glucémico. Estos hallazgos demuestran que el control de la enfermedad periodontal puede contribuir al tratamiento de la DM.

Fig 4. Efectos de la diabetes mellitus sobre la respuesta del huésped.

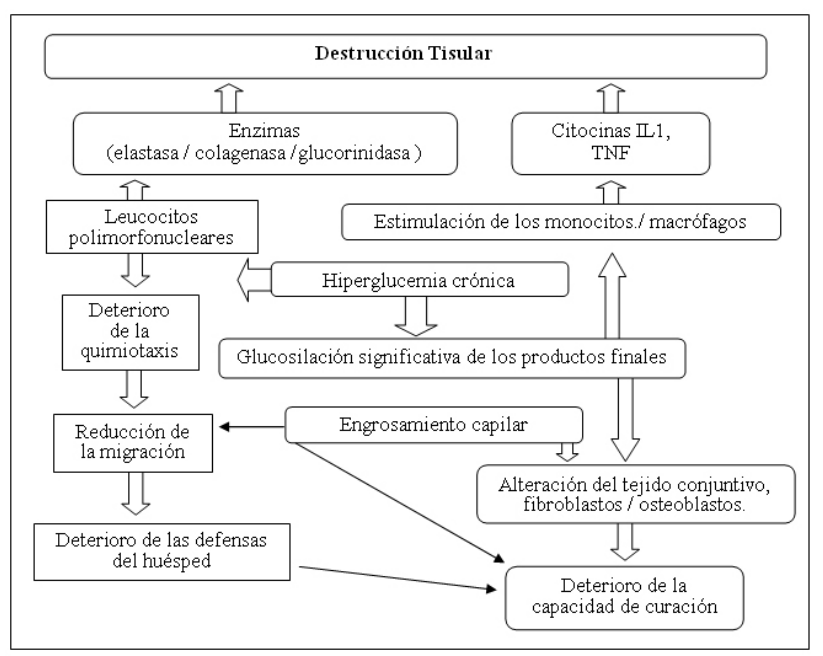

(Lindhe, Lang, Karring. Periodontología Clínica e Implantología Odontología. Editorial Médica Panamericana; 2009) 
Las lesiones inflamatorias importantes en la periodontitis grave contribuirían a la exacerbación de la diabetes. (15) Fig 4.

\section{CONCLUSIONES}

1. La EP puede considerarse un factor importante a tener en cuenta en la aparición de ciertas alteraciones sistémicas.

2. La enfermedad periodontal se asocia con resultados adversos del embarazo, debido a las alteraciones proinflamatorias que pueden resultar en una labor prematura y niños con bajo peso al nacer.

3. La enfermedad periodontal es capaz de predisponer a las personas a enfermedad cardiovascular, dada la abundancia de bacterias gram negativas y sus metabolitos, y las reacciones inmunes contra ellas.

4. La enfermedad periodontal se asocia con enfermedades respiratorias debido a la respuesta inflamatoria y la alteración de las condiciones microambientales que permiten la colonización e infección a mucosas por patógenos respiratorios y bacterias orales.

\section{CORRESPONDENCIA}

Carla Lola Pretel Tinoco

Jr. Pedro Remi 190. Urb. Ingeniería

San Martín de Porres. Lima-Perú.

Teléfono: (511) 5352100 / 983704480

Correo electrónico: pretel.carla@gmail.com

\section{REFERENCIAS BIBLIOGRÁFICAS}

1. Thomas M, Herbert F. Atlas a Color de Periodontología. Caracas: Editorial Amolca; 2009.

2. Mealey B, Koekkevold P. Medicina Periodontal. En: Carranza. Periodontología Clínica. 9 ed. México DF: McGraw-Hill Interamericana; 2004.p.243- 60

3. Lindhe, Lang, Karring. Periodontología Clínica e Implantología Odontológica. $5^{\circ}$ Edicion. Buenos Aires: Editorial Médica Panamericana; 2009.

4. Mealey BL. Influence of periodontal infections on systemic health. Periodontol 2000. 1999 Oct;21:197-209.

5. Gómez R, Ghezzi R, Romero R, Muñoz H, Tolosa J, Rojas I. Premature labor and intraamniotic infection. Clin Perinatol. 1995 Jun;22(2):281-342.

6. Ovalle A Enfermedad Periodontal: Relación con Parto Prematuro y Niño con Bajo Peso al Nacer. Rev Chil Periodon Oseoint, 2006;3(3):23-9.

7. Jeffcoat MK, Geurs NC, Reddy MS, Goldenberg RL, Hauth JC. Current evidence regarding periodontal disease as a risk factor in preterm birth. Ann Periodontol.
2001;6:183-8.

8. Maita, L., \& Castañeda, M. El embarazo y la enfermedad periodontal. Odontología Sanmarquina. 2000;1(16):1.

9. Isaac S, Gomes-Filho, Simone S, Eneida M, Cerqueira F, Eliesita C, et al. Periodontal Therapy and Low Birth Weight: Preliminary Results From an Alternative Methodologic. J Periodontol. 2010 Dec;81(12):1725-33.

10.Tejerina JM, Cuesta S, Menéndez M, Sicilia A. ¿Existe relación entre enfermedad cardiovascular y periodontitis? Av Periodon Implantol. 2003;16(3):113-9.

11.Guarda E. Enfermedad periodontal y cardiopatía coronaria. Boletín escuela de medicina Pontificia Universidad Católica de Chile. 2006;31(1).

12.Scannapieco F, Bush R, Paju S. Associations between periodontal disease and risk for atherosclerosis, cardiovascular disease and stroke. A systemic Review. Ann Periodontal 2003;8:38-53.

13.Rose L, Genco R, Mealey B, Cohen W. Periodontal Medicine. London: Editorial B.C. Decker; 2000.

14.Scannapieco F, Frawley N, Vacanti A. Control de la microflora microbial bucal para prevenir la neumonía en poblaciones con pacientes especiales.Inside Dentistry.2007;3(1):7-9.

15.Nishimura F, Iwamoto Y, Soga Y. The periodontal host response with diabetes. Periodontology 2000. 2007; 43:245-53.

Recibido : 06-08-2013

Aceptado: 24-11-2013 